\section{Horizontal flow of pore fluids}

SIR-Hanor, in his calculation ${ }^{1}$ of the density-driven subsurface movement of pore fluids near a salt dome on the Louisiana Gulf Coast, derived horizontal velocities of the order of $10 \mathrm{~m}$ per year at depths exceeding $1,000 \mathrm{~m}$. These velocities are large for a sedimentary basin Bethke et al. ${ }^{2}$ cite values measured in $\mathrm{cm}$ per year - even in the geologically disturbed environs of a salt dome. Indeed, they are gross overestimates which stem from the erroneous assumption of hydrostatic equilibrium in the fluid flow. We repeated Hanor's calculations using a model that does not invoke the assumption of hydrostatic equilibrium and obtained velocities smaller by a factor of thousands.

Although the assumption of hydrostatic equilibrium may lead to reasonable approximations of the absolute values of pressure, it is entirely inappropriate in predicting horizontal pressure gradients (horizontal components of "hydraulic force field" in Hanor's terminology) and the associated velocities of lateral densitydriven flow in deep basins. Indeed, the hydrostatic assumption (also sometimes referred to as the Dupuit approximation) is tantamount to the neglect of the resistance to vertical fluid flow or, equivalently, to the assumption that the permeability is relatively large in the vertical direction (comparable to or greater than the permeability in the horizontal direction). This assumption is not valid for the geological system under consideration.

In reality, the vertical permeability in deep sedimentary basins, evaluated over thick sequences of alternating sands and shales, is not large, even next to a salt dome, as Hanor himself has more recently implied ${ }^{3}$. Moreover, convective fluid overturn, which is typical of densitydriven fluid movement', will almost always be accompanied by a significant component of vertical flow, especially near an upward-tilting boundary such as a dome. Such a vertical flow will cause the system to deviate markedly from hydrostatic equilibrium.

In our calculations, we used a model of density-driven flow that combines the equation of continuity (conservation of mass) with Darcy's law for flow through porous media'. The model is not based on the hydrostatic assumption, and, moreover, recognizes that subsurface systems characteristically display highly anisotropic permeability behaviour when taken over thick sand/shale sequences, featuring very different values for permeability in the horizontal and vertical directions.

We sought to match as closely as possible Hanor's input parameters, including the imposed density distribution, the shape of the salt dome and values of all key physical properties. We used Hanor's value of $10^{-12} \mathrm{~m}^{2}$ (1 darcy) for the horiz- ontal permeability but varied the vertical permeability in the calculations. We also extended the calculations farther from the dome, using the reasonable constraint that the fluid density perturbation associated with the salt dome dies out gradually with horizontal distance.

As expected, our results agree with those of Hanor when the vertical permeability is set to a relatively large value,

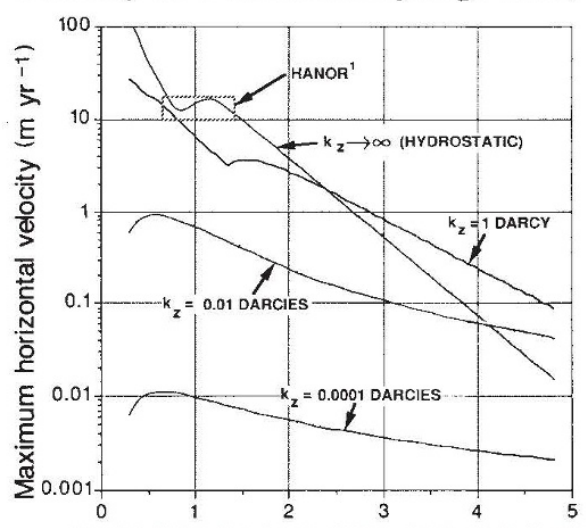

Radial distance from dome centreline ( $\mathrm{km}$ )

A comparison of our results with Hanor's data from ref. 1.

of the order of 1 darcy or greater (see figure). But with more realistic values of the vertical permeability between $10^{-16}$ and $10^{-17} \mathrm{~m}^{2}(0.00001-0.0001$ darcy), recently implied by Hanor as being reasonable for regions adjacent to salt domes, our calculated velocities decrease to between 0.1 and $1.0 \mathrm{~cm}$ per year. The calculations also show that the flow disturbance caused by density variations diminishes markedly with distance from the salt dome, indicating that this phenomenon is localized.

Chester Miller

Charles H. Hales

JAMES E. CLARK

RICHARD W. NOPPER JR

E. I. Du Pont De Nemours Inc,

Du Pont Experimental Station,

Wilmington,

Delaware 19880-0320, USA

HANOR REPLIES-Miller et al. misrepresent the purpose of my calculations ${ }^{1}$ which were made to demonstrate that inversions in pore-water density arising from variations in temperature, pressure and salinity are of sufficient magnitude to drive kilometre-scale vertical overturn of subsurface pore waters at the Iberia salt dome, Louisiana Gulf Coast. But the calculations of Miller et al. support my hypothesis. The limitations of the approximation I used were completely understood and are specifically mentioned in my paper. Further, subsequent published calculations by me and others ${ }^{3.5}$ using more rigorous techniques and more realistic boundary conditions have yielded comparable estimates for the range of the magnitude of hydraulic force which can be generated by spatial variations in porewater salinity and temperature around salt domes.

Contrary to the impression that may be given by Miller et al., I did not attempt to determine the fluid velocity field at Iberia because of the lack of adequate field information. To provide a preliminary order-of-magnitude estimate of fluid velocities which could result from the calculated forces, however, I did show that a horizontal hydraulic force of $50 \mathrm{~Pa} \mathrm{~m}^{-1}$ operating on fluids contained within a sand having an intrinsic permeability of $10^{-12} \mathrm{~m}^{2}$ could induce velocities in excess of $10 \mathrm{~m} \mathrm{yr}^{-1}$. This choice of permeability was an appropriate reference value because massive sands at the Iberia dome are known from direct measurement to have such permeabilities and because Iberia is surrounded by a sand-dominated, not a clay-dominated sequence (see my Fig. 3 ). My more recent work ${ }^{6}$ shows that even clay layers in the Louisiana Gulf coast can have effective vertical permeabilities two or three orders of magnitude higher than the values cited by Miller et al. as "more realistic", supposedly on my authority.

The detailed understanding of rates of deep fluid flow in the Gulf Coast will require more information than is generally available at present on the nature and local variability of driving forces and on the effects of media heterogeneity on permeability. The oversimplified conceptual and numerical modelling approach employed by Miller et al. is inadequate. Their conclusion, ". . . that the flow disturbance caused by density variations diminishes very markedly with radial distance from the salt dome, indicating that this phenomenon is very localized", is contradicted by published geological field evidence $^{7.8}$ clearly demonstrating that salt-dome-related solute transport is regional, not local. If Miller and his colleagues want to determine rates of subsurface fluid flow and solute transport in Louisiana, I recommend they begin monitoring the migration of the $7 \times 10^{9}$ litres of liquid hazardous wastes injected into the south Louisiana salt-dome province by their employer.

JEFFREY S. HANOR

Department of Geology and Geophysics,

Louisiana State University,

Baton Rouge, Louisiana 70803, USA

1. Hanor, J.S. Nature 327, 501-503 (1987)

2. Bethke, C.M., Harrison, W.J., Upson, C. \& Altaner, S.P. Science 239, 261-267 (1988).

3. Ranganathan, V. \& Hanor, J.S. Chem. Geol. 74, 173-188 (1988).

4. Miller, C. et al. Ground Water Monit. Rev. 6, 37-48 (1986)

5. Evans, D.G. \& Nunn, J.A. J. geophys. Res. 69, 1241312422 (1989).

6. Hanor, J.S. EOS 71, 509 (1990)

7. Hanor, J.S., Bailey, J.E., Rogers, M.C. \& Milner, L.R. Trans Gulf Coast Assoc. Geol. Soc. 35, 261-268 (1985)

8. Williamson, A.K., Grubb, H.F. \& Weiss, J.S. US Geol. Sun Water Res. Inv. Rep. 89-4071, (1990). 